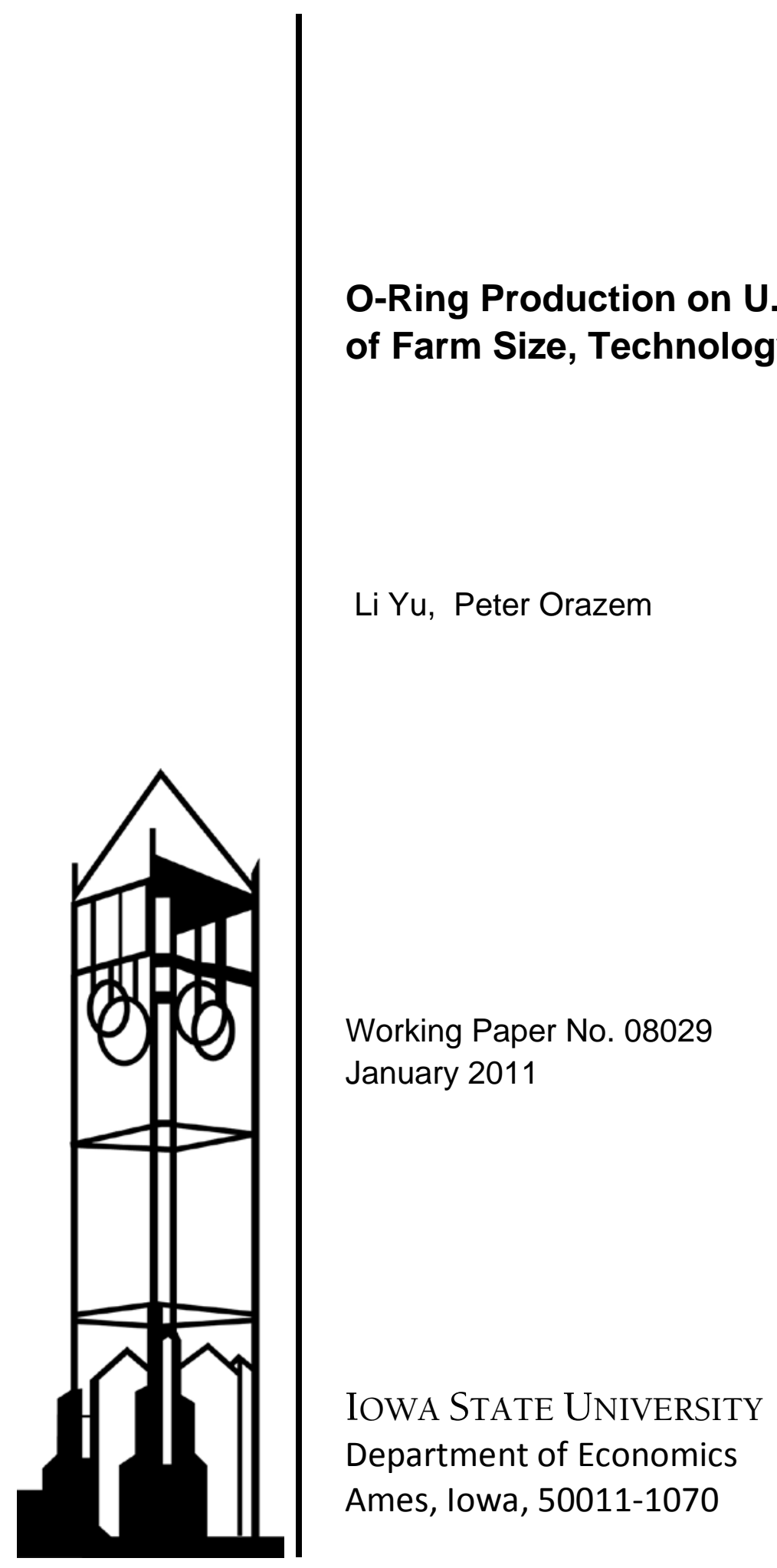

lowa State University does not discriminate on the basis of race, color, age, religion, national origin, sexual orientation, gender identity, sex, marital status, disability, or status as a U.S. veteran. Inquiries can be directed to the Director of Equal Opportunity and Diversity, 3680 Beardshear Hall, (515) 294-7612. 


\title{
O-Ring Production on U.S. Hog Farms: Joint Choices of Farm Size, Technology, and Compensation
}

\author{
Li Yu and Peter F. Orazem
}

January, 2011

\begin{abstract}
We hypothesize that hog production can be characterized by complementarities between new technologies, worker skills and farms size. Such production processes are consistent with Kremer's (1993) O-ring production theory in which a single mistake in any one of several complementary tasks in a firm's production process can lead to catastrophic failure of the product's value. In hog production, mistakes that introduce disease or pathogens into the production facility can cause a total loss of the herd. Consistent with predictions derived from the O-ring theory, we provide evidence that the most skilled workers concentrate in the largest and most technologically advanced farms and are paid more than comparable workers on smaller farms. These findings suggest that worker skills, new technologies and farm size are complements in production. The complementarities create returns to scale to large hog confinements, consistent with the dramatic increase in market share of very large farms over the past 20 years.
\end{abstract}

Key words: complementarity, O-ring, human capital, sorting, technology, farm size, wages, hogs, unobserved skill JEL: Q12; Q16; O33

Corresponding Author: Li Yu, China Center for Human Capital and Labor Market Research, Central University of Finance and Economics. liyu@cufe.edu.cn.

Acknowledgement: Li Yu is Assistant Professor, China Center for Human Capital and Labor Market Research, Central University of Finance and Economics. Beijing, China. Peter F. Orazem is University Professor, Department of Economics, Iowa State University, Ames, IA. This paper has benefited from comments from Terry Hurley, Jim Kliebenstein, John Lawrence, John Schroeter, and seminar participants at Iowa State University, the Midwest Economics Association and the American Association of Agricultural Economists. Funding support from the U.S. Department of Agriculture and the National Pork Board/Primedia Business is gratefully acknowledged. 


\section{Introduction}

Kremer’s (1993) O-ring production theory describes a process in which a single mistake in any one of several tasks in the firm's production process can lead to catastrophic failure of the product. ${ }^{1}$ Such production processes make inputs used in any one task natural complements to the inputs used in other tasks. The amount a worker can earn in performing one task will depend on the quality of the workers performing the other tasks. As a result, employees will seek to work with others of similar or greater skills because working with less-skilled workers risks wage loss from the greater likelihood of production errors.

This study argues that Kremer's production structure provides a useful framework for analyzing farmer choices regarding farm size, technology adoption and personnel. As farm size and technological complexity increase, the number of separate production tasks increases and the cost of mistakes rises. Therefore, workers with higher skills will be used more intensively in more complex and technologically advanced production processes. Farms with O-ring production processes will hire more skilled workers, adopt newer and more complex technologies and will have the largest scale of production. In competitive labor markets, their higher levels of labor productivity will result in higher wages for their employees.

O-ring production processes are consistent with recent incidences of massive recalls of agricultural commodities. E. coli tainted lettuce was recalled in 2006. Later that year, E-coli contaminated spinach sickened consumers in 25 states, and another spinach recall occurred from salmonella contamination a year later. In 2007, tainted wheat gluten used in cat food and chicken feed led to massive recalls of poultry and pet food and the curtailment of food ingredient imports from China. The slaughter of sick or crippled cattle led to the recall of 145 million pounds of beef in 2008. In 2010, 
potential Salmonella contamination led to the recall of nearly $2 \%$ of the annual U.S. egg production. ${ }^{2}$ These cases show that mistakes in hygiene, diagnosis, segregation, quality control, or any number of other individual tasks performed as part of an agricultural production process can lead to the loss of the entire crop.

Given the importance of the O-ring production process as a conceptual tool in economics, ${ }^{3}$ past research has tended to focus on testing a single prediction at a time. Pekkarinen (2002) and Dalmazzo, Pekkarinen and Scaramozzino (2007) found that more complex metal production processes increase worker pay in Finland, consistent with one prediction of the theory. Several papers have found evidence that more educated farmers are first to adopt new technologies, supporting a second prediction that human capital and technology are complementary inputs. ${ }^{4}$ Manufacturing studies have shown a positive correlation between average wages and information technology investments, consistent with a third prediction of the theory. ${ }^{5}$ Yet another strand of research initiated by Henry Moore (1911) and corroborated by Brown and Medoff (1989) has found a positive correlation between wages and firm size, a fourth prediction from the theory. ${ }^{6}$ Finally, Stoneman and Kwon (1994); Colombo and Mosconi (1995); Idson and Oi (1999); and McBride and Key (2003) report evidence that larger firms adopt more advanced technologies, consistent with a fifth prediction. None of the papers provides a comprehensive test of all the predictions of the O-ring hypothesis in the context of a single market. We undertake such a test using three surveys of employees on hog farms in the United States conducted in 1995, 2000 and 2005. The hog market provides a particularly appropriate test of the O-ring theory. First, a large number of hog farms compete in a relatively homogeneous product market. Though the hog market has experienced a large decline in farm numbers since 1995, there were still sixty nine thousand farms producing hogs as of 
2004 (USDA 2005), and so there is a strong presumption that the output is priced competitively. ${ }^{7}$ Farms enter, remain in, or exit the market without considering the actions of rival farms. At the same time, technological advances have occurred rapidly, and so farms vary dramatically in the number and the variety of technologies used. Farms vary dramatically in size, although the market share of farms with annual production of at least 10,000 hogs has increased from $22 \%$ to $86 \%$ since $1991{ }^{8}$ Farms also vary in the skills of their employees, from laborers to veterinary doctors. Finally and most importantly, hog farm production is subject to the sort of catastrophic failures represented by the O-ring process: lapses in sanitation, litter segregation, feed, or swine health maintenance can lead to substantial output losses including the potential destruction of the entire herd.

Our empirical methodology allows us to test whether workers with more skills, whether measured by observable attributes (education or sector-specific work experiences) or unobserved but inferable from econometric structure, congregate on farms that are simultaneously larger, use more complex technologies, and pay higher wages. We can test whether skill complementarities implied by the O-ring production process lead to more specialization on larger and more complex farms. The evidence presented is consistent with these predictions, providing strong support that the O-ring production theory can characterize production on U.S. hog farms. The evidence also indicates why new technologies and their complementarities with farm size and worker skills have contributed to the dramatic rise of large hog confinements over the past 20 years. 


\section{Implications of the O-ring Theory: Complementarity between Technology}

\section{Adoption, Firm Size and Wages}

Kremer (1993) provides a simple and intuitive framework within which to analyze the implications of complementarities among inputs. Production takes place as a series of $t$ indivisible tasks where technological complexity increases in $t$. We assume that there are multiple possible tasks so that $t>1 .^{9}$ Each of the tasks requires the same amount of labor whose performance levels $q$ are exogenously determined and crucial to the output level $y .{ }^{10}$ We consider the problem faced by a competitive farm that maximizes profit by choosing the degree of technology complexity, $t$, and the taskspecific skill level of workers, $q_{i}$ :

$$
\max _{t, q_{i}}\left(\prod_{i=1}^{t} q_{i}\right) t B(t)-\sum_{i=1}^{t} w\left(q_{i}\right)
$$

$B(t)$ is the value of output produced per task with $B^{\prime}(t)>0$ and $B^{\prime \prime}(t)<0, \frac{d t}{d q}>0$.

The final output price is normalized to be one, consistent with a market where farms are price takers, and so the variation in output value per task is due entirely to farm productivity differences and not to market power over price.

Individual wages depend on the worker skills, $q_{i}$, with $w^{\prime}\left(q_{i}\right)>0$. The labor market is competitive so the wage per unit of skill is set exogenously.

The first term in (1) is the farm's output level, $y=\left(\prod_{i=1}^{t} q_{i}\right) t B(t)$, which we will use as a measure of farm size. The O-ring production process leads to complementarity between workers. The marginal product of workers in task $i$ positively depends on the level of output of workers in any other task, as shown by

$$
\frac{d^{2} y}{d q_{i} d\left(\prod_{j \neq i} q_{j}\right)}=t B(t)>0
$$

As a result, workers will have an incentive to select farms with coworkers whose 
skills are no worse than theirs. From the employers' perspective, farms also have an incentive to hire workers with relatively homogeneous skills due to the complementary production function. If workers are freely mobile, all workers on a farm will end up with the same level of skill in equilibrium, and so $q_{i}=q_{j}=q ; i, j=$ $1,2, \ldots, t ; i \neq j$. While all workers on a farm will be homogeneous in skill at level $q$, the level of skills will differ across farms of different sizes and technological complexities.

This sorting of workers by skill across farms provides two predictions about the cross-sectional pattern of workers and technologies that we can confirm or reject in the data. The first prediction is

Hypothesis 1: The most skilled workers will be employed on farms with A) the most complex technologies; $B$ ) the largest annual production; and C) wages at the upper tail of the wage distribution for any given skill.

To derive the three elements of the hypothesis, we apply two simplifications to the farm's optimization problem in (1). First, because worker skills on a farm are homogenous, we impose $q_{i}=q_{j}=q$. Second, we assume that this sorting of workers happens before the beginning of production such that we take worker skills exogenously determined for the moment. Note that the second simplification will not alter our conclusions. The simplified objective function (1) is

$$
\max _{t} q^{t} t B(t)-t w(q)
$$

The first order condition with respect to tasks, $t$ is

$$
q^{t} t B(t) \ln q+q^{t} B(t)+q^{t} t B^{(t)}-w(q)=0
$$

With competitive markets, firms will expect to earn zero profit, and so

$$
q^{t} B(t)-w(q)=0 .
$$


Inserting condition (5) into (4) implies that

$$
\ln q=-\frac{B^{\prime}(t)}{B(t)}
$$

Equation (6) shows that technological complexity $t$ is an implicit function of skill level $q$. Because $B^{\prime}(t)>0$ and $B^{\prime \prime}(t)<0, \frac{d t}{d q}>0$, justifying $\left.A\right)$ in Hypothesis 1 that more skilled workers will seek employment on farms with more complex production processes.

Given that all the workers on a farm will have the same level of skill, $q$, the farm's production function is $y=q^{t} t B(t)=f(q, t(q))$. The total derivative of $y$ with respect to skill is

(7) $\frac{\partial y}{\partial q}=f_{1}+f_{2} \frac{\partial y}{\partial q}=t^{2} q^{t-1} B(t)+\left[q^{t} t B(t) \ln q+q^{t} B(t)+q^{t} t B^{\prime}(t)\right] \frac{\partial t}{\partial q}>0$

Therefore, we can justify part B) of Hypothesis 1 that more skilled workers congregate on larger farms. Hypothesis $1 C$ ) that more skilled workers will be paid higher wages is justified by the assumption that $\boldsymbol{w}^{\prime}\left(\boldsymbol{q}_{\boldsymbol{i}}\right)>0$. Nevertheless, it also follows from totally deriving the zero profit condition (5) with respect to $q$ : the marginal product of skill $\frac{\partial y}{\partial q}$ must be equal to its marginal cost $\frac{\partial w}{\partial q}$. is

The second prediction implied by the sorting of workers by skill across farms

Hypothesis 2: Farm-level decisions on technological complexity (t), farm size (y) and wages (w) are all positively correlated.

This hypothesis suggests that all three decisions complement each other so that a farm that chooses to be at the upper tail of any one choice will tend to be at the upper tail of the other two choices also. We demonstrate the hypothesis by considering all bivariate correlations in turn. Note first that larger farms have more 
complex production processes.

$$
\frac{d y}{d t}=q^{t} t B(t) \ln q+q^{t} B(t)+q^{t} t B^{\prime}(t)=w(q)>0 \text {, which follows from the }
$$

first-order-condition (4), at any skill level $q$, and so $\operatorname{Cov}(y, t)>0$.

To show that farms using more complex technologies will pay workers higher wages, take the natural log of both sides of the zero profit condition (5),

$$
\ln w(g(t))=t \ln q+\ln B(t)=-t \frac{B^{\prime}(t)}{B(t)}+\ln B(t),
$$

where $q=g(t)$ and $g(t)$ is the inverse function of $t(q)$ which is increasing in $t$ according to (6). Taking derivatives with respect to $w$ in (8), we obtain

$$
\frac{\partial w}{\partial t}=w\left(-t \frac{B^{\prime \prime}}{B}+t\left(\frac{B^{\prime}}{B}\right)^{2}\right)>0 \text {, and so } \operatorname{Cov}(w, t)>0 .
$$

To show size of operation rises with wages paid on the farm, we first define an inverse function $q=v(w), v^{\prime}(w)>0$, evaluated at the wage $w$ that maximizes profit. The zero profit condition can be rewritten as $y\{v(w), t[v(w)]\}=t[v(w)] w$. Taking derivatives on both sides of this equation with respect to $w$,

$$
\frac{\partial y}{\partial w}=\frac{\partial y}{\partial t} \frac{\partial v}{\partial w}+\frac{\partial y}{\partial t} \frac{\partial t}{\partial v} \frac{\partial v}{\partial w}=t+w \frac{\partial t}{\partial v} \frac{\partial v}{\partial w}>0 \text {, and so } \operatorname{Cov}(y, w)>0 \text {. Because all }
$$

three bivariate relationships are positive, the three variables must covary as well.

A third prediction can be derived which relates the relative dispersion of the three choices that should obtain in cross sectional data:

Hypothesis 3: Even if skills are symmetrically distributed, wages and farm size will be skewed right. Furthermore, given that $\operatorname{Cov}(t, w)>0$, the distribution of farm sizes must be more dispersed than the distribution of wages.

Output and wages are both homogeneous of degree $t$ in $q$. As long as the number of possible tasks or technologies $t$ is greater than one, output $y$ and wages $w$ will be convex in $q$. Therefore, the size distribution of hog farms is skewed right with 
a few very large farms and many small farms, even if worker skills are symmetrically distributed.

In addition, the zero profit condition $y=t w(q)$ combined with the positive correlation between $t$ and $w$ given by Hypothesis 2 imply that the variance of $y$ is linearly related to the distributions of $t$ and $w$. Define Y to be a vector of technology complexity $t$ and wage $w, Y=\left[\begin{array}{c}t \\ w\end{array}\right]$. Firm size will be a function of vector $\mathrm{Y}, y=$ $h(Y)$. Applying the zero profit condition, $y=w t$, and using the delta method, the variance of firm size will be of the form $\operatorname{var}(y)=\nabla h(Y)^{T} \sum \nabla h(Y)$ where $\nabla \mathrm{h}(\mathrm{Y})$ is the corresponding gradient of $\mathrm{h}(\mathrm{Y})$ and $\sum$ is the variance-covariance matrix of $\mathrm{Y}$. Then, $\operatorname{var}(y)=\left[\begin{array}{ll}w & t\end{array}\right]\left[\begin{array}{cc}\sigma_{t}^{2} & \rho_{w t} \sigma_{w} \sigma_{t} \\ \rho_{w t} \sigma_{w} \sigma_{t} & \sigma_{w}^{2}\end{array}\right]\left[\begin{array}{c}w \\ t\end{array}\right]$ where $\sigma_{j}^{2}$ denotes the variance of variable $j=y, t, w$, and $\rho_{w t}>0$ denotes the correlation coefficient between technology and wages. Evaluating at sample means $\mu_{j}, j=t, w$ we have $\sigma_{y}^{2}=$ $\mu_{w}^{2} \sigma_{t}^{2}+\mu_{t}^{2} \sigma_{w}^{2}+2 \mu_{w} \mu_{t} \rho_{w t} \sigma_{w} \sigma_{t}$. With $t>1$, the average of $t, \mu_{t}>1$, and therefore $\sigma_{y}^{2}>\sigma_{w}^{2}$ holds in our application. That means that farm size will be more dispersed than farm wages.

\section{Data}

We test these hypotheses using survey data from employees on U.S. hog farms in 1995, 2000, and 2005 collected from subscribers to National Hog Farmer Magazine. ${ }^{11}$ Because the subscribers are not a representative sample of all hog farm employees and because the propensity to respond to surveys may differ by year and farm size, we weight each survey response to conform to the size distribution of employees on U.S. hog farms as reported in the Agricultural Census Data (ACD) of 
the US Department of Agricultural (USDA). ${ }^{12}$

The survey includes questions about worker demographics, past experience on hog farms, job tenure, and education and attributes of each worker's farm including farm size and technology usage. Consequently, the data set includes all the information necessary to test for possible complementarities among worker skills and farm productive attributes consistent with the O-ring production process.

\section{Distribution of Technology Complexity, Farm Size and Wages}

We first present summary information on the dependent variables of interest. The distributions of wages, technologies and output are all skewed to the right. Output has the broadest dispersion. All three variables are positively correlated. Therefore, the data are broadly consistent with the patterns predicted by the O-ring theory. We will put these hypotheses to more rigorous tests in the next section.

There were seven technologies included on the surveys that were available to hog farmers every year between 1995 and 2005. The technologies are used to improve gene pool (AI), target nutrition programs (PF), curb disease spread (AIAO, MSP) and increase output (EW). We use the total number of technologies used on a farm as a measure of production complexity. Two new technologies Auto Sorting System (AS) and Parity Based Management (PBM) were only included in the 2005 questionnaire, and so we constrain the available technology set to the first seven options. Of those seven, the average number of adopted technologies used on hog farms increased from 2.7 in 1995 to 3.5 in 2005 . Over that same time frame, the distribution of employees has shifted toward farms using more technologies. Overall, the employment distribution by total number of technologies is right skewed with half of hog farm employees working for farms using no more than three technologies.

The employment share by farm size category is presented in table 2. Farm size 
also varies over a broad range. The smallest farms produce less than 1000 pigs a year. The largest farms produce more than 25,000 pigs. The distribution of employment across farm sizes is shown in the bottom row of table 2. The distribution is skewed right, similar to the distribution of technology usage.

Because farm size is a categorical variable, we need to transform it into a continuous measure to generate appropriate distribution statistics. Using the midpoint of the corresponding farm size range as the continuous representation of the categorical data, the corrected skewness is 2.99. The corresponding corrected skewness measure of the wage distribution in table 3 is 1.89 , and so both farm size and wages are skewed right as required by Hypothesis 3.

Larger farms tend to adopt more technologies as shown in the last column of table 2. The smallest farms use an average of 2.3 technologies, only half of the number of technologies used on the largest farms. The sample wage distributions reported in table 3 show that wages rise with the number of technologies used. Wages also tend to rise with farm size although the average size decreases somewhat at the highest wage groups. The positive bivariate correlations among wages, technologies and farm size are consistent with Hypothesis 2.

Over time, average salaries have risen on hog farms. Rising salaries have coincided with rising farm size and increased technology use over the period. The time pattern is also consistent with Hypothesis 2.

Table 4 summarizes the other variables included in our analysis. Women comprise $8.8 \%$ of hog farm employees. The average hog farm worker has completed at least a junior college program, similar to averages for the labor force as a whole. Tenure and PrevExp indicate the working time on the current farm and previous experience on other hog farms respectively. Average tenure is nearly nine years with 
41 percent of employees having had prior hog farm work experience. Over half the workers were FarmBorn, a dummy variable indicating the employee was raised on a hog farm. Sixty-three percent of the hog farm employees work in the Midwest which serves as the baseline region; the others being located in the Northeast, Southeast and West. $^{13}$

Our theoretical model suggests that more skilled workers will have an incentive to sort into larger and more technologically advanced farms. Figure 1 shows the size, wage and technology distributions for the most and least educated employees on hog farms. Workers with at least a bachelor's degree are more likely to work on larger and more technologically advanced farms and are paid more than those who did not complete high school. Although not a formal test, the patterns in Figure 1 are consistent with a process whereby the most skilled sort into farms with other skilled workers, more advanced technologies, larger farms and higher wages. In the next section, we present the formal tests of the theory's predictions.

\section{Econometric Testing of the O-ring Production Function}

We propose an estimable model which allows simultaneous choices of technological complexity, farm size and wages, given the observed and unobserved human capital attributes of the workers and other observed farm characteristics. In another context, Abowd et al. (1999) found that individual heterogeneity explains a large proportion of the wage variation between different firm sizes. In our O-ring production function, we assume that skills include both observable and unobservable components. Both observed and unobserved skills should positively affect output, wages and technical complexity, predictions that can be tested formally with a structural econometric 
model.

We consider three latent dependent variables: $t_{i}^{*}$ is the number of technologies used by the farm employing individual $i$; $s_{i}^{*}$ is the size of individual $i$ 's farm; and $w_{i}^{*}$ is the salary paid to individual $i$. We posit that the joint choices of $t_{i}^{*}, s_{i}^{*}$ and $w_{i}^{*}$ take the form

$$
\begin{aligned}
& t_{i}^{*}=x_{i} \beta_{t}-u_{t i} \\
& s_{i}^{*}=x_{i} \beta_{s}-u_{s i} \\
& w_{i}^{*}=x_{i} \beta_{w}-u_{s i} \\
& \left(\begin{array}{l}
u_{t i} \\
u_{s i} \\
u_{w i}
\end{array}\right) \sim N\left(\left(\begin{array}{l}
0 \\
0 \\
0
\end{array}\right),\left(\begin{array}{ccc}
1+\lambda_{t}^{2} \sigma^{2} & \lambda_{t} \lambda_{s} \sigma^{2} & \lambda_{t} \lambda_{w} \sigma^{2} \\
\lambda_{t} \lambda_{s} \sigma^{2} & 1+\lambda_{s}^{2} \sigma^{2} & \lambda_{w} \lambda_{s} \sigma^{2} \\
\lambda_{t} \lambda_{w} \sigma^{2} & \lambda_{w} \lambda_{s} \sigma^{2} & 1+\lambda_{w}^{2} \sigma^{2}
\end{array}\right)\right) .
\end{aligned}
$$

where $x_{i}$ is a vector of individual and farm characteristics specified in Table 4 with coefficient vectors $\beta_{t}, \beta_{s}$ and $\beta_{w}$ to be estimated in technology adoption, farm size and wage rate equations respectively. Hypothesis 1 can be tested based on the signs of the parameters attached to observable skills. A finding of positive signs in all of the equations is evidence consistent with the hypothesis that productive skills (i.e. skills that raise wages) are complementary with both farm size and technology.

The random disturbance terms are of the form $u_{i j}=\lambda_{j} e_{i j}+\zeta_{i j}, j=t, s, w$. Errors are composed of two parts: the unobserved ability component of skills, $e_{i j} \sim N\left(0, \sigma^{2}\right)$, and a pure random factor $\zeta_{i j}$ that varies across choices and is assumed to be an independent draw from a standard normal distribution. Because $e_{i j}$ affects firm choices on farm size, technology adoption intensity and offered wages in the same direction, the signs of the parameters $\lambda_{t}, \lambda_{s}$, and $\lambda_{w}$ will show whether unmeasured worker skills positively influence all three dependent variables. The 
correlation coefficient between any two random errors out of the three equations is

$$
\rho_{k l}=\frac{\lambda_{k} \lambda_{l} \sigma^{2}}{\sqrt{1+\lambda_{k}^{2} \sigma^{2}} \sqrt{1+\lambda_{l}^{2} \sigma^{2}}}, \quad k, l=t, s, w, k \neq l .
$$

A finding that all three error correlation conditions hold, $\rho_{t s}>0, \rho_{s w}>$

0 and $\rho_{t w}>0$, is consistent with Hypothesis 2 that the farm size, technology

intensity and wages paid are positively correlated because of worker sorting according to unobserved skills.

Testing Hypothesis 3 requires identifying the relative magnitudes of $\lambda_{t}, \lambda_{s}$, and $\lambda_{w}$. We cannot identify the absolute sizes of the $\lambda_{k}$ but we can identify their relative magnitudes. By normalizing $\lambda_{t}$ at one, equation (10) shows that we can identify $\lambda_{s}$, and $\lambda_{w}$, given knowledge of the variance of unobserved human capital $\sigma^{2}$. In particular, we can then determine if $\lambda_{s}>\lambda_{w}$ which will imply that the distribution of farm sizes is more dispersed than the distribution of wages.

\section{Estimation}

Our measures of technical complexity, farm size and wages are categorical. For example, the latent continuous variable $t_{i}^{*}$ is not directly observable, but the number of technologies used on the farm is observed as a discrete category, $t_{i}$. We define it as:

$$
\begin{aligned}
t_{i} & =0 \quad \text { if } \quad t_{i}^{*}<a_{0} \\
& =1 \quad \text { if } \quad a_{0} \leq t_{i}^{*}<a_{1} \\
& \ldots \\
& =7 \quad \text { if } \quad a_{6} \leq t_{i}^{*} \quad, a_{c}>a_{c-1}, \forall c=\{1,2, \ldots, 6\}
\end{aligned}
$$

The $a_{c}$ are unknown cut-points parameters to be estimated. The unconditional probability that individual $i$ works on a farm adopting $k$ technologies is 


$$
\begin{aligned}
& \operatorname{Pr}\left(t_{i}=k\right)=\Phi\left(\frac{x_{i} \beta_{t}-a_{k-1}}{\sqrt{1+\lambda_{t}^{2} \sigma^{2}}}\right)-\Phi\left(\frac{x_{i} \beta_{t}-a_{k}}{\sqrt{1+\lambda_{t}^{2} \sigma^{2}}}\right), \\
& \forall k=\{0,1,2, \ldots, 7\}, \quad a_{-1}=-\infty, \quad a_{7}=+\infty,
\end{aligned}
$$

$\Phi(\cdot)$ denotes the cumulative density function of the standard normal distribution.

Farm size and wages are also divided into categories from zero to seven. The corresponding probability for farm size and wages in a specific category can be written according to (12). The joint estimation can be treated as a trivariate ordered probit model based on equations (9) to (12). The log likelihood function is $L L=\prod_{i=1}^{n} \omega_{i} \ln \operatorname{Pr}\left(t_{i}=k, s_{i}=m, w_{i}=l \mid x_{i}\right), \quad k, m, l=0,1, \ldots, 7$.

where

$$
\begin{aligned}
& \operatorname{Pr}\left(t_{i}=k, s_{i}=m, w_{i}=l \mid x_{i}\right) \\
& =\operatorname{Pr}\left(a_{k-1} \leq t_{i}<a_{k}, a_{m-1} \leq s_{i}<a_{m}, a_{l-1} \leq w_{i}<a_{l} \mid x_{i}\right) \\
& =\operatorname{Pr}\left(t_{i}<a_{k}, s_{i}<a_{m}, w_{i}<a_{l} \mid x_{i}\right) \\
& -\operatorname{Pr}\left(t_{i}<a_{k-1}, s_{i}<a_{m}, w_{i}<a_{l} \mid x_{i}\right) \\
& -\operatorname{Pr}\left(t_{i}<a_{k}, s_{i}<a_{m-1}, w_{i}<a_{l} \mid x_{i}\right) \\
& -\operatorname{Pr}\left(t_{i}<a_{k}, s_{i}<a_{m}, w_{i}<a_{l-1} \mid x_{i}\right) \\
& +\operatorname{Pr}\left(t_{i}<a_{k-1}, s_{i}<a_{m-1}, w_{i}<a_{l} \mid x_{i}\right) \\
& +\operatorname{Pr}\left(t_{i}<a_{k-1}, s_{i}<a_{m}, w_{i}<a_{l-1} \mid x_{i}\right) \\
& +\operatorname{Pr}\left(t_{i}<a_{k}, s_{i}<a_{m-1}, w_{i}<a_{l-1} \mid x_{i}\right) \\
& -\operatorname{Pr}\left(t_{i}<a_{k-1}, s_{i}<a_{m-1}, w_{i}<a_{l-1} \mid x_{i}\right), k, l, m=0,1, \ldots, 7 .
\end{aligned}
$$

$\operatorname{Pr}\left(t_{i}=k, s_{i}=m, w_{i}=l \mid x_{i}\right)$ is the cumulative density function evaluated for individual $i$ paid wage $l$, employed on a hog farm of size $m$, and using $k$ technologies, conditional on realizations of $x_{i} . \omega_{i}$ is the sampling weight assigned to individual $i$. Given our joint normality assumption governing the errors, the corresponding probability density function is 


$$
\begin{aligned}
& f_{Y}(k, m, l)=\frac{1}{(2 \pi)^{2 / n} \sqrt{\operatorname{det} \Sigma}} e^{-\frac{1}{2}(Y-\bar{y})^{T} \Sigma^{-1}(Y-\bar{y})}, \\
& Y=\left(t_{i}^{*}, s_{i}^{*}, w_{i}^{*}\right)^{T}, \\
& \bar{y}=\left(x \beta_{t}, x \beta_{s}, x \beta_{w}\right)^{T}, \\
& \Sigma=\left(\begin{array}{ccc}
1+\lambda_{t}^{2} \sigma^{2} & \lambda_{t} \lambda_{s} \sigma^{2} & \lambda_{t} \lambda_{w} \sigma^{2} \\
\lambda_{t} \lambda_{s} \sigma^{2} & 1+\lambda_{s}^{2} \sigma^{2} & \lambda_{w} \lambda_{s} \sigma^{2} \\
\lambda_{t} \lambda_{w} \sigma^{2} & \lambda_{w} \lambda_{s} \sigma^{2} & 1+\lambda_{w}^{2} \sigma^{2}
\end{array}\right) .
\end{aligned}
$$

$Y$ is the vector of latent dependent variables representing technological complexity, farm size and wages. $\bar{y}$ is the corresponding mean vector of $Y . T$ denotes the transpose of the matrix. $\Sigma$ is the variance - covariance matrix of $Y$ defined by equation (9). We use the Generalized Linear Latent and Mixed Models (GLLAMM) procedure in STATA 9.1 to estimate the model. ${ }^{14}$

Several additional assumptions are necessary to make the estimation tractable. As noted above, $\lambda_{t}$ is normalized at one.The remaining parameters $\beta_{t}, \beta_{s}, \beta_{w}, \sigma^{2}, a_{c}$, $\lambda_{s}$ and $\lambda_{w}, c=0,1, \ldots, 6$ are identified subject to that normalization. In addition, estimation time rises rapidly with the number of parameters to be estimated and the likelihood of convergence decreases with added complexity (Grilli and Rampichini 2003). We performed some prior investigations of the best parsimonious representation of each of the three dependent variables in (9). As is common with earnings functions, the wage equation was linear in schooling and quadratic in experience. Linear terms in schooling and experience proved sufficient for the technology equation. Farm size was also linear in experience but had significant linear and quadratic terms in schooling. 
Farms specializing in farrow-to-feeder or feeder-to-finish operations would be expected to have fewer technology options than would farms that take pigs all the way from farrow to finish pigs. This is not a major issue if farms make the choice of type of operation contemporaneously with the choice of technology mix. Nevertheless, it is plausible that type of farm operation is correlated with the unobservable employee attributes that also affect farm size or wages. We replicated our analysis of model (9) using a restricted sample that included only farrow-to-finish farms. The results are shown in Tables A1 in the Appendix. Again, qualitative results and conclusions are consistent with those obtained with the full sample, and so our results are not driven by type of operation.

\section{Empirical Findings}

Coefficient estimates from the trivariate ordered probit are shown in table 5. We first assess whether the results are consistent with Hypothesis 1 that human capital will simultaneously raise technical complexity, firm size and wages. Coefficients on observed schooling are positive in all three equations. The effect of schooling on selecting a large farm is positive but diminishing with the peak marginal effect between 12 and 13 years of schooling. Prior experience on hog farms also increases wages, technology use and farm size.

Our other two human capital measures have inconsistent effects, although there are plausible explanations. Having been raised on a farm increases farm size and technical complexity, but it lowers wages. It is possible that farm raised workers have another source of returns on the farm, namely that they are atypically working

on a farm of a parent or relative in anticipation of eventually taking over the operation. In fact, farm-raised workers are more likely to say that they plan to have their own 
operations in the future.

Given that we control for all prior experience on hog farms, our experience measure is effectively a measure of age. Consistent with the expectations of the human capital investment model, we find that incentive to adopt technology declines with age (Huffman, 2001). Incentives to select employment on larger farms also decline with age. However, wages rise at a declining rate with age, a common finding in the earnings function literature. The implied peak wage on hog farms occurs around age 51 and then declines. Taken together, we have that the oldest workers in the sample atypically work on smaller farms with few technological advances and are paid less than are younger workers on larger and more technologically advanced farms, especially younger workers with prior experience on hog farms.

As with observed measures of human capital, unobserved human capital also positively influences all three dependent variables. The estimated variance of unobserved farm-specific individual ability $\sigma^{2}$ is statistically significant. With $\lambda_{t}$ restricted to be 1 , the finding that $\lambda_{s}$ and $\lambda_{w}$ are both positive and significant means that unmeasured individual abilities affect choices of technological complexity, farm size and wage rates in the same direction. Taken together, the evidence on both observed and unobserved skills are broadly supportive of Hypothesis 1. Human capital simultaneously increases wages, technologies and farm size.

Hypothesis 2 is concerned with the correlations among the three dependent variables. The O-ring theory predicts that more skilled workers will congregate in more technologically complex firms and larger firms and evidence that they will be rewarded with higher wages. The implied pair-wise correlation coefficients among the errors in the technology adoption, farm size and wage rate equations computed 
using equation (10) are reported at the bottom of table 5. The standard errors are calculated using the delta method. All three correlations are positive and statistically significant, consistent with Hypothesis 2.

The relative magnitudes of the $\lambda s$ provide a test of Hypothesis 3 that the farm size distribution is more dispersed than the wage distribution. Because the $\lambda s$ are attached to farm-specific individual unobservables, $e_{i j}$, the larger coefficient on farm size $\left(\lambda_{s}=1.05\right.$, which is nearly twice the coefficients on the wage rate $\left(\lambda_{w}=0.54\right)$, implies that holding worker skills fixed, there is a greater dispersion of farm sizes than of wages. Hypothesis 3 cannot be rejected.

Note that the error terms include both individual skills and how those skills match with unobserved productive firm attributes. The positive correlation in errors implies not only that unobserved worker skills are complementary with farm size and technological innovations, but that the unobserved farm productivities sought out by those atypically skilled workers are also leading to positive correlations between wages, technologies and farm size. Similar positive correlations in unobserved wages and unobserved productivities have been documented in other industries (Haltiwanger, Lane and Spletzer, 2007; Abowd et al., 1999; Pekkarinen, 2002; Dalmazzo, Pekkarinen and Scaramozzino, 2007 ). Furthermore, Dalmazzo (2002) found that wage differentials for identical workers increase with heterogeneity in technologies across firms. Our finding that $\rho_{t w}>0$ suggests that as variation in technological complexity increases across hog farms, the wage gap between farms at the upper and lower tales of technology adoption will increase, even for worker skills that are observationally equivalent. 
An additional finding is that women are paid less than observationally equivalent men. However, women are also significantly less likely to work in the larger and more technologically complex operations that pay more. That suggests part of the female disadvantage is due to a lower propensity to seek out or be accepted for jobs in the largest and most technologically advanced farms. Those farms are also rapidly increasing their market share. If the lower probability that women enter the largest and most technologically complex farms persists, then the gender wage gap in pork production will be rising in the future.

\section{Conclusion and Discussion}

This study shows that choices of farm size, technology adoption, compensation and skill utilization on U.S. hog farms are consistent with Kremer’s (1993) O-ring production theory. A process in which a single mistake in any one of several tasks in a farm's production process can lead to catastrophic failure of the product's value generates natural complementarities between worker skills, farm size, and technological complexity. Workers of like skill are sorted into individual firms with the more skilled labor allocated to larger and higher paying firms with more complex production processes. Using survey data from hog farm employees from 1995-2005, we find evidence that technology adoption and farm size are complements with both observed and unobservable components of worker human capital and evidence that workers on larger and more technologically advanced farms are paid more than otherwise comparably skilled workers on smaller and less technology intensive farms.

The market share for hog farms with annual production exceeding 10,000 head increased from 22\% in 1991 to $86 \%$ at the time of the last survey. Our results show why technological advances in hog production have been driving the dramatic 
increase in the market share of large hog farms. The new technologies have allowed more concentrated production, but as farms have become larger, they create a need for a more skilled and highly compensated work force. Larger farm size increases the risk of catastrophic financial losses. As insurance against operator error, farms adopting the more advanced technologies must hire workers with more skilled workers and pay them higher wages. In competitive markets, the productivity gains accruing to larger farms using advanced technologies will be offset by higher wages, the higher costs of absorbing the liability of catastrophic failure, and potentially, by higher local land prices. ${ }^{15}$ If higher input prices do not fully offset the profit advantages from improved productivity, then additional entry of the larger farms will eventually drive the economic rents earned by the initial large farm entrants to zero. However, if higher input costs do fully offset the productivity advantages, then an equilibrium can exist in which smaller farms earn zero economic profits by having lower productivity and paying lower input prices while larger farms earn zero economic profits by having higher productivity and higher input costs. ${ }^{16}$

A possible constraint to the further expansion of large hog farms is the need to attract skilled labor to relatively remote worksites favored by large confinements. As documented by Artz (2003), these are the rural counties that have experienced the largest brain drain in the past. The greater the difficulty in accessing and retaining skilled workers in rural areas, the more the rents earned from the productivity gains associated with larger and more technologically complex farms will be captured in wages. Some programs have been created to train college students and prepare them with practical and managerial skills needed on large hog operations such as the Swine Science Online program and the Professional Swine Manager/Technician Certification and Education Program (Miller, 2010). An increasingly available supply of skilled 
labor will increase the tendency toward larger and more technologically complex hog operations in the United States. 


\section{References}

Abdulai, Awudu and Wallace Huffman. 2005. “The Diffusion of New Agricultural Technologies: The Case of Cross-bred-cow Technology in Tanzania”. American Journal of Agricultural Economics 87: 645-695.

Abowd, John, Francis Kramarz and David Margolis. 1999 . "High Wage Workers and High Wage Firms”. Econometrica 67: 251-337.

Acemoglu, Daron. 2002. “Technical Change, Inequality, and the Labor Market”. Journal of Economic Literature 40: 7-72.

Artz, Georgeanne. 2003. “Rural Area Brain Drain: Is It a Reality?” CHOICES, 4(December):11-16.

Brown, Charles and James Medoff. 1989. “The Employer Size-wage Effect”. Journal of Political Economy 97: 1027-1059.

Caselli, Francesco and Wilbur Coleman II. 2001. “Cross-country Technology Diffusion: The Case of Computers”. American Economic Review 91: 328-335.

Colombo, Massimo and Mosconi, Rocco. 1995. “Complementarity and Cumulative Learning Effects in the Early Diffusion of Multiple Technologies”. The Journal of Industrial Economics 43: 13-48.

Dalmazzo, A. 2002. “Technological complexity, wage differentials, and unemployment”. The Scandinavian Journal of Economics 104(4): 515-530.

Dalmazzo, A., T. Pekkarinen and P. Scaramozzino. 2007. “O-ring Wage Inequality”. Economica 74: 515-536.

Dorfman, Jeffrey. 1996. “Modeling Multiple Adoption Decisions in a Joint Framework”. American Journal of Agricultural Economics 78: 547-557.

Dunne, Timothy, Lucia Foster, John Haltiwanger and Kenneth Troske. 2004. "Wage and Productivity Dispersion in United States Manufacturing: The Role of 
Computer Investment”. Journal of Labor Economics 22: 397-429.

Foster, Andrew and Mark Rosenzweig. 1995. "Learning by Doing and Learning from Others: Human Capital and Technical Change in Agriculture”. Journal of Political Economy 103: 1176-1209.

Griliches, Zvi. 1957. "Hybrid Corn: An Exploration in the Economics of Technological Change”. Econometrica 25: 501-522.

Grilli, Leonardo and Carla Rampichini. 2003.” Alternative Specifications of Multivariate Multilevel Probit Ordinal Response”. Journal of Educational and Behavioral Statistics 28: 31-44.

Haltiwanger, J.C., J.I. Lane and J.R. Spletzer. 1989. “Productivity Differences across Employers: The Roles of Employer Size, Age and Human Capital”. AEA Papers and Proceedings 89(2): 94-98.

Haltiwanger, John C., Julia I. Lane and James R. Spletzer. 2007. “Wages, Productivity, and the Dynamic Interaction of Businesses and Workers.” Labour Economics 14(3): 575-602.Huffman, Wallace. E. 2001. Human Capital: Education and Agriculture. Handbook of Agricultural Economics. Vol 1(1): 333381. and Stephanie Mercier. 1991. "Joint Adoption of Micro Computer Technologies: An Analysis of Farmers' Decision”. The Review of Economics and Statistics 73: 541-546.

Huffman, W.E. (2001), “Human capital: education and agriculture.” in Gardner, B. and G. Rausser, (eds.). Handbook of Agricultural Economics, Amsterdam: Elsevier Science, pp. 334-381.

Hurley, Terrance M., James Kliebenstein, Peter F. Orazem. 1999. “The Structure of Wages and Benefits in the U.S. Pork Industry”. American Journal of 
Agricultural Economics 81: 144-163.

Idson, Todd and Walter Oi. 1999.” Workers Are More Productive in Larger Firms”. American Economic Review Papers and Proceedings 89: 104-108.

Iranzo, Susana, Fabiano Schivardi and Elisa Tosetti. 2008. "Skill Dispersion and Firm Productivity: An Analysis with Employer-Employee Matched Data”. Journal of Labor Economics 26: 247-285.

Khanna, Madhu, Onesime Faustin Epouhe and Robert Hornbaker. 1999. “Site Specific Crop Management: Adoption Patterns and Incentives”. Review of Agricultural Economics 21: 455-472.

Kremer, Michael. 1993. “The O-Ring Theory of Economic Development”. The Quarterly Journal of Economics 108: 551-575.

Krueger, Alan. 1993. "How Computers Changed the Wage Structure? Evidence from Micro Data: 1984-1989”. Quarterly Journal of Economics 108: 33-60.

Lawrence, John D. and Glenn Grimes. 2007. "Production and Marketing Characteristics of U.S. Pork Producers, 2006" Iowa State University Working Paper \#7014. June.

McBride, William D. and Nigel Key. 2003. Economic and Structural Relationship in U.S. Hog Production. Agricultural Economic Report No. (AER818). USDA.Miller, Dale. 2010. New Programs Target Industry Careers. National Hog Farmer.

Moore, Henry L.1911. Laws of Wages: An Essay in Statistical Economics. New York: Macmilln.

Oi, Walter Y. and Todd Idson L.1999. Firm Size and Wages. The Handbook of Labor Economics, Elsevier, edition 1, Vol 3, number 3.

Pekkarinen T. 2002. “Complexity, Wages, and the O-ring Production Function: 
Evidence from Finnish Panel Data”. Labour Economics 9: 531-546.

Reily, Kevin T. 1995. "Human Capital and Information: the Employer Size Wage Effect”. Journal of Human Resources 30: 1-18.

Rabe-Hesketh, Sophia, Anders Skrondal and Andrew Pickles. 2004. GLLAMM

Manual, U.C. Berkeley Division of Biostatistics working paper series.

Rabe-Hesketh, Sophia and Anders Skrondal. 2006. "Multilevel Modeling of Complex Survey Data”. Journal of the Royal Statistical Society 169: 805-827.

Stoneman, Paul and Myung-Joong Kwon. 1994. "The Diffusion of Multiple Process Technologies”. The Economic Journal 104: 420-431.

USDA. Farms, land in farms, and livestock operations, 2004 summary. 2005. US Department of Agriculture, National Agricultural Statistics Service.

Wozniak, Gregory. 1987. “Human Capital, Information, and the Early Adoption of New Technology”. The Journal of Human Resources 22: 101-112. 1993. “Joint Information Acquisition and New technology adoption: Late Versus Early Adoption”. The Review of Economics and Statistics 75: 438-445.

Yu, L., T. Hurley, J. Kliebenstein and P. Orazem. 2008. "Testing the complementarity and substitutability among multiple technologies: the case in the U.S. hog farms". Department of Economics, ISU Economics Working Paper. 
Table 1. Fraction of Employees on Hog Farms Using Various Technologies

\begin{tabular}{|c|c|c|c|c|c|c|c|c|}
\hline \multirow{2}{*}{ Number } & \multirow{2}{*}{ Name } & \multirow{2}{*}{ Notation } & \multicolumn{2}{|c|}{1995} & \multicolumn{2}{|c|}{2000} & \multicolumn{2}{|c|}{2005} \\
\hline & & & Mean & Std Dev & Mean & Std Dev & Mean & Std Dev \\
\hline 1 & Artificial Insemination & AI & 0.41 & 0.49 & 0.61 & 0.49 & 0.69 & 0.46 \\
\hline 2 & Split Sex Feeding & SSF & 0.32 & 0.47 & 0.45 & 0.50 & 0.35 & 0.48 \\
\hline 3 & Phase Feeding & $\mathrm{PF}$ & 0.48 & 0.50 & 0.54 & 0.50 & 0.49 & 0.50 \\
\hline 4 & Multiple Site Production & MSP & 0.22 & 0.41 & 0.33 & 0.47 & 0.29 & 0.45 \\
\hline 5 & Early Weaning & EW & 0.09 & 0.29 & 0.22 & 0.42 & 0.23 & 0.42 \\
\hline 6 & All in / All out & AIAO & 0.57 & 0.50 & 0.64 & 0.48 & 0.57 & 0.50 \\
\hline 7 & Computer Usage & $\mathrm{CU}$ & 0.59 & 0.49 & 0.69 & 0.46 & 0.72 & 0.45 \\
\hline 8 & Auto Sorting Systems & AS & . & . & . & . & 0.03 & 0.16 \\
\hline \multirow[t]{2}{*}{9} & Parity Based Management & PBM & . & . & . & . & 0.19 & 0.39 \\
\hline & Total Number of Technologies & - & 2.74 & 1.64 & 3.49 & 1.86 & 3.52 & 1.86 \\
\hline & & Mean & \multicolumn{6}{|c|}{$3.18(2.06)$} \\
\hline & Total camplo & Median & \multicolumn{6}{|c|}{$3(1.25)$} \\
\hline & 1 & Variance & \multicolumn{6}{|c|}{$3.28(4.18)$} \\
\hline & & Skewness & \multicolumn{6}{|c|}{$0.36(2.99)$} \\
\hline
\end{tabular}

Note: Statistics are weighted. “.” represents that the category is not asked in the survey. Technology complexity is represented by the number of technologies adopted on hog farms. The distribution is weighted by sampling weights such that it reflects the population distribution of hog farms. Auto Sorting system technology (AS) and Parity Based Management (PBM) in 2005 are censored in the variable of technology complexity. Technology complexity ranges from zero to seven in each of the survey years. 
Table 2. Size Class and Frequencies

\begin{tabular}{|c|c|c|c|c|}
\hline \multirow[t]{2}{*}{ Code } & \multirow{2}{*}{$\begin{array}{l}\text { Size Class } \\
\text { (number of pigs } \\
\text { produced ) }\end{array}$} & \multirow[t]{2}{*}{ Frequency } & \multicolumn{2}{|c|}{$\begin{array}{c}\text { Average Number of Used } \\
\text { Technologies }\end{array}$} \\
\hline & & & Mean & Std dev \\
\hline & less than 1000 & 15.67 & 2.32 & 1.46 \\
\hline 1 & 1,000 to 1,999 & 15.44 & 2.25 & 1.54 \\
\hline 2 & 2,000 to 2,999 & 17.04 & 2.99 & 1.69 \\
\hline 3 & 3,000 to 4,999 & 12.52 & 3.55 & 1.67 \\
\hline 4 & 5,000 to 9,999 & 21.25 & 3.36 & 1.73 \\
\hline 5 & 10,000 to 14,999 & 3.08 & 3.96 & 1.61 \\
\hline 6 & 15,000 to 24,999 & 2.54 & 4.12 & 1.67 \\
\hline 7 & 25,000 or more & 12.46 & 4.58 & 1.81 \\
\hline- & Total & $100 \%$ & & \\
\hline \multirow{4}{*}{-} & \multirow{4}{*}{ Statistics of Size } & Mean & 2.90 & \\
\hline & & Median & $3(0$ & \\
\hline & & Variance & 7.45 & \\
\hline & & Skewness & 0.48 & \\
\hline
\end{tabular}

\footnotetext{
Note: Variable Size takes the value of $0,1, \ldots, 7$ with corresponding meaning shown in the second column. The estimates of frequency and technology complexity are weighted using sampling weights. An alternative continuous measure of size is obtained by using the mid-point of the size class in place of the size code. The numbers in parentheses are the distribution statistics corresponding to the continuous farm size measure (unit: 10,000 heads of pigs).
} 
Table 3. Positive Relationships between Farm Size, Technological Complexity and Wages

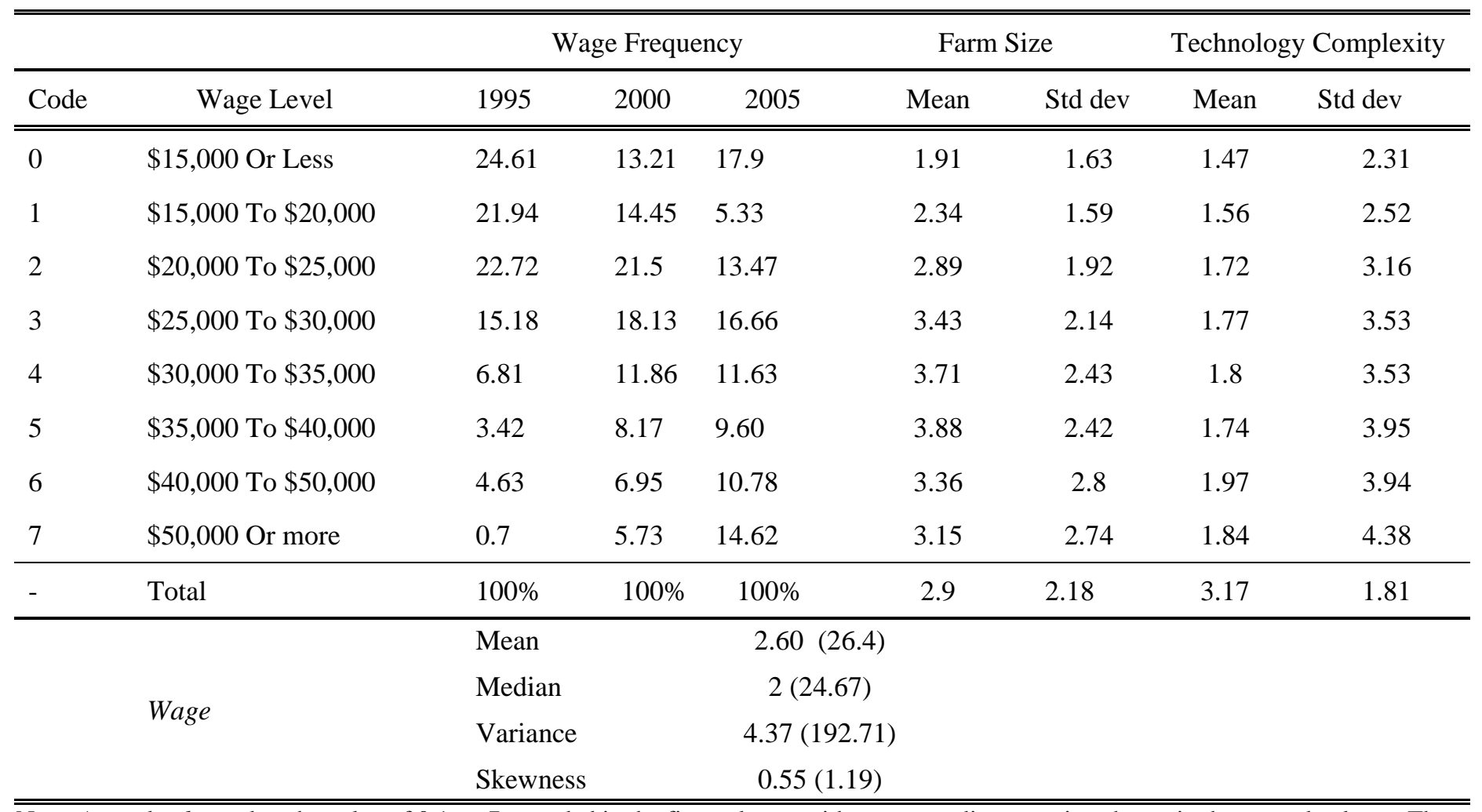

Note: Annual salary takes the value of $0,1, \ldots, 7$ as coded in the first column, with corresponding meaning shown in the second column. The estimates of wage frequency, farm size and technology complexity are weighted using sampling weights. A continuous representation of the categorical wage is generated by applying the midpoint of the associated pay range. These are converted to real terms using the Consumer Price Index. Distribution statistics for the continuous variant of the real wage are reported in parentheses. 
Table 4.Characteristics of Employees in the U.S. Hog Industry, 1995-2005

\begin{tabular}{|c|c|c|c|}
\hline Variables & Description & Mean & Std Dev \\
\hline Technology & Number of technologies used $(0,1, \ldots 7)$ & 3.18 & 1.81 \\
\hline Size & Farm size category $(0,1, \ldots 7)$ & 2.90 & 2.18 \\
\hline Wage & Salary range $(0,1, \ldots 7)$ & 2.60 & 2.09 \\
\hline Female & Gender of workers, equal to 1 if the worker is a female & 0.10 & 0.30 \\
\hline Education & Schooling years & 14.10 & 2.51 \\
\hline Experience & Working experience (age - education years - 6) & 17.52 & 11.24 \\
\hline PrevExp & Dummy variable, equal to 1 if previously working full time in a hog farm & 0.45 & 0.50 \\
\hline FarmBorn & Dummy variable, equal to 1 if raised in a hog farm & 0.50 & 0.50 \\
\hline Northeast & Dummy variable, equal to 1 if located in the northeast & 0.09 & 0.28 \\
\hline Southeast & Dummy variable, equal to 1 if located in the southeast & 0.14 & 0.35 \\
\hline West & Dummy variable, equal to 1 if located in the west & 0.15 & 0.35 \\
\hline
\end{tabular}

Note: The numbers are the weighted mean and the standard deviation. The statistics of the variables are weighted and are based on the surveys in 1995,2000 and 2005. The education level reflected in the survey is categorical. Variable Education is measured by he continuous schooling years (SY) of a worker is defined in the following way. SY $=9$ if she is a high school drop out. SY $=12$ if she is a high school graduate. SY = 14 if she attended the four year college but did not complete or had other equivalent diploma, such as completing vocational technical /school program or junior college program. SY $=16$ if she is has a bachelor's degree. SY $=18$ if she has master degree. Sy $=20$ if she has a Ph.D. degree holder or a Doctor of Veterinary Medicine. 
Table 5Trivariate Orderd Probit Model for Employees Working on Farms

\begin{tabular}{|c|c|c|c|c|c|c|}
\hline & Technology & & Farm Size & & Wage & \\
\hline Variables & $\beta_{t}$ & $\mathrm{t}$-value & $\beta_{s}$ & t-value & $\beta_{w}$ & t-value \\
\hline \multicolumn{7}{|c|}{ (a) Regression parameters } \\
\hline Female & -0.391 & $-2.73 * * *$ & -0.316 & $-1.91^{*}$ & -0.455 & $-3.19 * * *$ \\
\hline Education & 0.130 & $6.72^{* * *}$ & 0.728 & $4.57 * * *$ & 0.197 & $8.38^{* * *}$ \\
\hline Education $^{2}$ & & & -0.030 & $-5.15 * * *$ & & \\
\hline Experience & -0.017 & $-4.11 * * *$ & -0.012 & $-2.63 * *$ & 0.067 & $5.39 * * *$ \\
\hline Experience $^{2}$ & & & & & -0.001 & $-4.01 * * *$ \\
\hline PrevExp & 0.360 & $4.04^{* *}$ & 0.347 & $3.90 * * *$ & 0.389 & $4.79 * * *$ \\
\hline FarmBorn & 0.104 & 1.16 & -0.068 & -0.81 & -0.171 & $-2.10 * *$ \\
\hline Northeast & -0.327 & $-1.90 *$ & -0.405 & $-2.58^{* *}$ & 0.209 & 1.28 \\
\hline Southeast & 0.004 & 0.03 & 0.191 & 1.24 & 0.211 & $1.85^{*}$ \\
\hline West & 0.447 & $3.68 * *$ & 0.371 & $2.60 * *$ & -0.099 & -0.71 \\
\hline Year 2000 & 0.551 & $5.26^{* * *}$ & 1.046 & $8.87^{* * *}$ & 0.523 & $5.66^{* * *}$ \\
\hline Year 2005 & 0.625 & $5.23^{* * *}$ & 1.145 & $8.57 * * *$ & 0.790 & $7.01^{* * *}$ \\
\hline \multicolumn{7}{|c|}{ (b) Thresholds } \\
\hline$\alpha_{0}$ & -0.414 & -1.32 & -0.414 & -1.32 & -0.414 & -1.32 \\
\hline$\alpha_{1}$ & 0.853 & $2.89^{* * *}$ & 0.853 & $2.89 * * *$ & 0.853 & $2.89 * * *$ \\
\hline$\alpha_{2}$ & 1.787 & $5.91^{* * *}$ & 1.787 & $5.91^{* * *}$ & 1.787 & $5.91 * * *$ \\
\hline$\alpha_{3}$ & 2.395 & $7.64^{* * *}$ & 2.395 & $7.64^{* * *}$ & 2.395 & $7.64^{* * *}$ \\
\hline$\alpha_{4}$ & 3.064 & $9.28 * * *$ & 3.064 & $9.28 * * *$ & 3.064 & $9.28^{* * *}$ \\
\hline$\alpha_{5}$ & 3.753 & $10.52^{* * *}$ & 3.753 & $10.52^{* * *}$ & 3.753 & $10.52^{* * *}$ \\
\hline$\alpha_{6}$ & 4.424 & $11.46^{* * *}$ & 4.424 & $11.46^{* * *}$ & 4.424 & $11.46^{* * *}$ \\
\hline \multicolumn{7}{|c|}{ (c) Variance parameters } \\
\hline \multirow{3}{*}{$\begin{array}{l}\sigma^{2} \\
\lambda_{s} \\
\lambda_{w}\end{array}$} & 0.653 & \multicolumn{5}{|l|}{$[0.173]^{* * *}$} \\
\hline & 1.049 & \multicolumn{5}{|l|}{$[0.261]^{* * *}$} \\
\hline & 0.543 & \multicolumn{5}{|l|}{$[0.102]^{* * *}$} \\
\hline \multicolumn{7}{|c|}{ (d) Correlation Coefficients } \\
\hline$\rho_{t s}$ & 0.406 & \multicolumn{5}{|l|}{$[0.027]^{* * *}$} \\
\hline$\rho_{s w}$ & 0.260 & \multicolumn{5}{|l|}{$[0.035]^{* * *}$} \\
\hline$\rho_{t w}$ & 0.252 & \multicolumn{5}{|l|}{$[0.034]^{* * *}$} \\
\hline
\end{tabular}


Figure 1 Histograms of most educated and least educated employment by number of technologies, farm size and wages

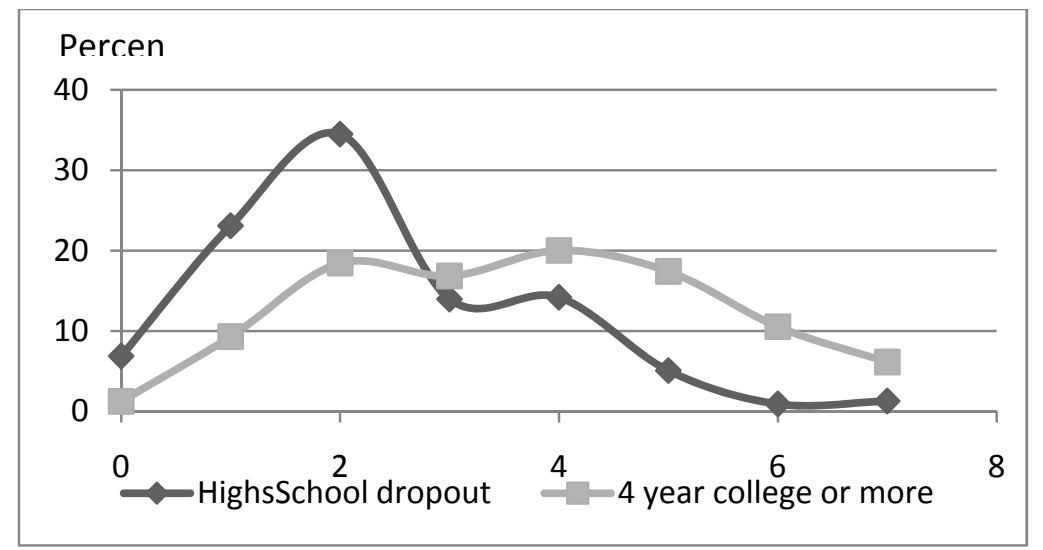

Figure 1(a) histogram of employment by number of adopted technologies

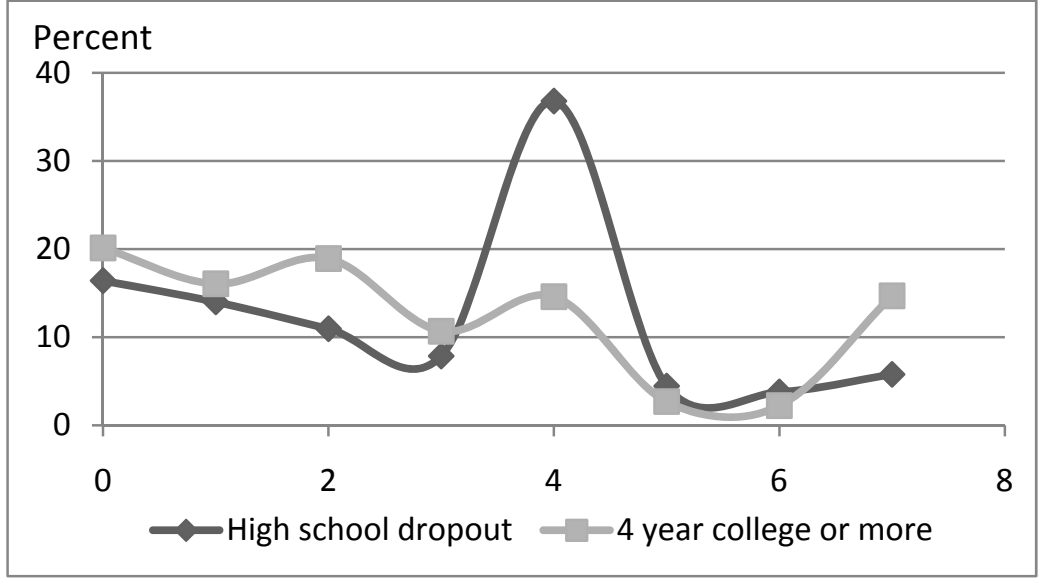

Figure 1(b) histogram of employment by farm size

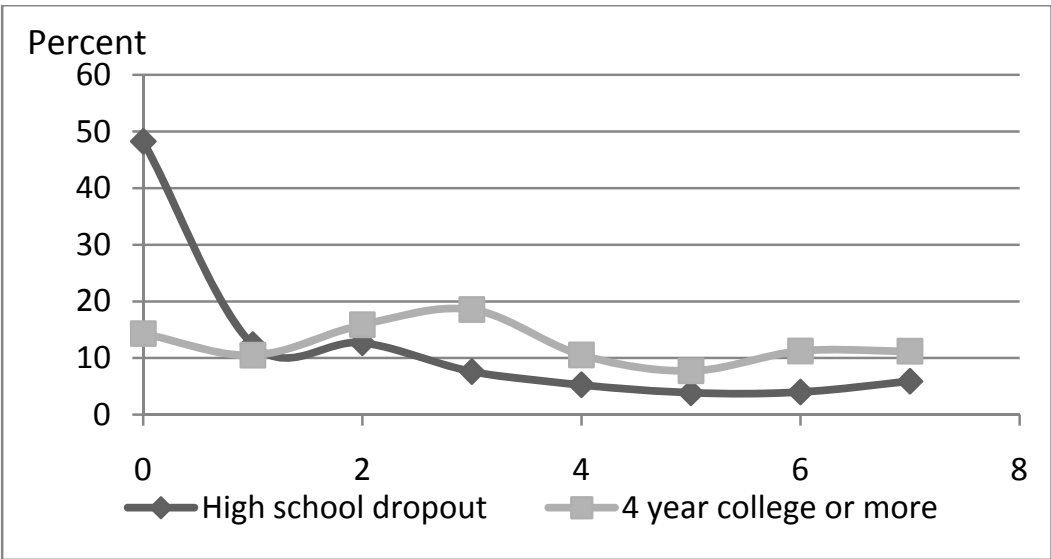

Figure 1(c) histogram of employment by wage 


\section{APPENDIX}

Table A1Trivariate OrderdProbit Model for Employees Working on Farms Which Have Farrow-to-Finish Operations

\begin{tabular}{|c|c|c|c|c|c|c|}
\hline & Technol & & Farm Size & & Wage & \\
\hline Variables & $\beta_{t}$ & t-value & $\beta_{s}$ & t-value & $\beta_{w}$ & t-value \\
\hline \multicolumn{7}{|c|}{ (a) Regression parameters } \\
\hline Female & -0.470 & $-1.87 *$ & -0.135 & -0.59 & -0.945 & $-4.86 * * *$ \\
\hline Education & 0.136 & $4.55^{* * *}$ & 0.525 & $2.64 * * *$ & 0.242 & $8.88^{* * *}$ \\
\hline Education $^{2}$ & & & -0.022 & $-3.12 * * *$ & & \\
\hline Experience & -0.012 & $-2.07 * *$ & -0.012 & $-2.08 * *$ & 0.076 & $4.70^{* * *}$ \\
\hline Experience $^{2}$ & & & & & -0.001 & $-2.94 * * *$ \\
\hline PrevExp & 0.600 & $4.07^{* * *}$ & 0.319 & $2.76^{* * *}$ & 0.353 & $3.43 * * *$ \\
\hline FarmBorn & 0.030 & 0.23 & -0.118 & -1.08 & -0.203 & $-1.98 * *$ \\
\hline Northeast & -0.255 & -1.14 & -0.374 & $-1.79 *$ & 0.225 & 1.19 \\
\hline Southeast & -0.026 & $42-0.13$ & 0.101 & 0.54 & -0.022 & -0.14 \\
\hline West & 0.389 & $2.24^{* *}$ & 0.285 & $1.63^{*}$ & -0.281 & $-1.74 *$ \\
\hline Year 2000 & 0.746 & $4.13^{* * *}$ & 1.023 & $6.77^{* * *}$ & 0.447 & $3.52^{* * *}$ \\
\hline Year 2005 & 0.908 & $4.90 * * *$ & 1.161 & $6.60 * * *$ & 0.815 & $5.55^{* * *}$ \\
\hline \multicolumn{7}{|c|}{ (b) Thresholds } \\
\hline$\alpha_{0}$ & -0.479 & -1.05 & 1.714 & 1.24 & 3.317 & $7.84^{* * *}$ \\
\hline$\alpha_{1}$ & 0.802 & $1.88^{*}$ & 2.466 & $1.77^{*}$ & 4.007 & $9.26^{* * *}$ \\
\hline$\alpha_{2}$ & 1.868 & $4.08 * * *$ & 3.313 & $2.36^{* *}$ & 4.665 & $10.55^{* * *}$ \\
\hline$\alpha_{3}$ & 2.591 & $5.24^{* * *}$ & 3.824 & $2.71^{* * *}$ & 5.292 & $11.62^{* * *}$ \\
\hline$\alpha_{4}$ & 3.327 & $6.12 * * *$ & 4.827 & $3.37 * * *$ & 5.692 & $12.26^{* * *}$ \\
\hline$\alpha_{5}$ & 4.150 & $6.71^{* * *}$ & 5.028 & $3.50^{* * *}$ & 6.073 & $12.72^{* * *}$ \\
\hline$\alpha_{6}$ & 4.894 & $7.16^{* * *}$ & 5.193 & $3.60 * * *$ & 6.666 & $13.08^{* * *}$ \\
\hline
\end{tabular}

(c) Variance parameters

\begin{tabular}{lll}
$\sigma^{2}$ & 1.137 & {$[0.498]^{* * *}$} \\
$\lambda_{s}$ & 0.763 & {$[0.280]^{* * *}$} \\
$\lambda_{w}$ & 0.370 & {$[0.111]^{* * *}$} \\
\hline
\end{tabular}

(d) Correlation Coefficients

$\begin{array}{lll}\rho_{t s} & 0.460 & {[0.036]^{* * *}} \\ \rho_{s w} & 0.231 & {[0.043]^{* * *}} \\ \rho_{t w} & 0.267 & {[0.042]^{* * *}}\end{array}$

Note: * Statistic significant at $10 \%$. ${ }^{* *}$ Statistic significant at 5\%; *** Statistic significant at $1 \%$. The number of observations is 1282. $\rho_{k l}, k, l=t, s, w, k \neq l$ are calculated according to formula (10) with estimated standard errors obtained using delta method.

a. the number is the standard error of the corresponding estimate. 


\footnotetext{
${ }^{1}$ The name recalls how a failed O-ring led to the destruction of the Space Shuttle Challenger.

${ }^{2}$ USDA food recalls are reported at http://www.usrecallnews.com/section/recalled-food.

${ }^{3}$ As of July 23, 2010, there are 785 citations to the original paper on Google Scholar.

${ }^{4}$ See Griliches (1957); Wozniak (1987, 1993); Huffman and Mercier (1991); Dorfman (1996); Foster and Rosenzweig (1995); Khanna et al. (1999); and Abdulai and Huffman ( 2005). Huffman (1999) presented a comprehensive review.
}

${ }^{5}$ Examples include Kruege (1993); Reily (1995); Caselli and Coleman II (2001) and Dunne et al. (2004). Acemoglu (2002) reviews the literature.

${ }^{6}$ Oi and Idson (1999) provide a review of this literature.

${ }^{7}$ Forward and futures markets help even isolated producers to expand the pool of buyers, reach new markets and expand sales opportunities where buyers bid against each other for hogs, equipment and materials. This financial channel makes the hog market more competitive because sellers need not have fixed buyers in order to market their hogs.

${ }^{8}$ Lawrence and Grimes (2007) present time series of market shares by farm size in the U.S. hog industry.

${ }^{9}$ In our empirical work, we will use the number of technologies to represent the number of tasks, and so the reader can interpret tasks and technologies as synonyms.

${ }^{10}$ In Kremer's model, $q \in(0,1)$ represents the expected proportion of the maximum possible value the product retains if the worker performs the task.

11 The survey had 1,538 respondents in 1995, 877 in 2000 and 639 in 2005.

${ }^{12}$ Consistent with the USDA classifications, each employee in our survey is placed into one of eight regions and one of the three farm size categories. The number of employees who have either full time or part time jobs on hog farms is taken as the population universe. The weights are computed as follows: there are $N$ employees in total in the US and $n_{j}$ of them in region-size cell $j$. The proportion of employees on hog farms which have region and size attributes in the $j^{\text {th }}$ cell is then $\frac{n_{j}}{N}$. The comparable number of employees in the same region-size cell $j$ in our sample is $s_{j}$. Each worker in the sample is then assigned a probability weight $\frac{n_{j}}{s_{j}}$. The USDA cells originally included eighteen regions and four size classifications. However, some of the region-size cells contained only a small number of sampled employees, and so we aggregated 
some of the region-size cells. Our eight regions are categorized as follows: 1. IL 2. IN 3. IA 4. MN 5. MO, TX, OK and AR 6. OH, WI and MI 7. NE 8 all other states. Farm size was divided into three levels in 1995, small: less than 3,000 pigs per year; medium: 3,000 to 9,999 pigs per year; and large: more than 10,000 pigs per year. For the 2000 and 2005 year surveys, farm size is divided into two levels, small: less than 10,000 pigs per year; and large: more than 10,000 pigs per year. Weights based on the 1992 Census were used for the 1995 survey responses, and the 1997 Census was used to weight the 2000 and 2005 survey responses.

${ }^{13}$ States included in the mid-west: IA, IL, IN, MN, MO, ND, NE, OH, SD, WI; in the northeast: CT,DC, DE, MA, MD, ME, MI, NH, NJ, NY, PA, RI, VT; in southeast: AL,FL, GA, KY, LA, MS, NC, SC, TN, VA, WV; and in the west: AK, AR, AZ, CA,CO, HI, ID, KS, MT, NM, NV, OK, OR, TX, UT, WA, WY.

${ }^{14}$ We use the Newton-Raphson method and adaptive quadrature to approximate the likelihood function by numerical integration (Rabe-Hesketh et al. 2004). Sample weights are assigned to each individual employee to obtain the robust standard errors (Rabe-Hesketh et al. 2006).

${ }^{15}$ In separate work, the authors have confirmed that large hog farms are sited in areas with flat topographies, low population density, milder January and July temperatures, and low July humidity. If such sites are rare relative to farmer demands for appropriate sites for large hog confinements, the land price will be bid up.

${ }^{16}$ In the model, we assumed zero profit conditions in a competitive market. Note that if more complex technologies only involved more risk of failure, farmers would have no incentive to adopt. The technologies must raise productive efficiency by reducing death loss, curbing disease spread, increasing feed efficiency, improving meat quality, increasing litter size, or allowing economies of scale. Competition will force the rents from these productivity advantages to be absorbed by higher prices for complementary inputs such as land and skilled labor, but farmers will earn better than normal economic profit until the markets fully adjust. 